\title{
Validation of the Brief Multidimensional Life Satisfaction SCAle in Patients with Chronic Diseases
}

\author{
A. Büssing ${ }^{1}$, J. Fischer ${ }^{1}$, A. Haller ${ }^{1}$, P. Heusser ${ }^{2}$, T. Ostermann ${ }^{1}$, P. F. Matthiessen ${ }^{1}$ \\ ${ }^{1}$ Chair of Medical Theory and Complementary Medicine, Faculty of Medicine, University of Witten/Herdecke, Germany \\ ${ }^{2}$ Institute for Complementary Medicine (KIKOM), University of Bern, Imhoof Pavillon, Inselspital, Bern, Switzerland
}

\begin{abstract}
Objective: We intended to determine the reliability of a brief life satisfaction scale in a sample of patients with chronic diseases, and to analyze its external validity. Methods: Reliability and factor analysis of the 8-item 'Brief Multidimensional Life Satisfaction Scale' (BMLSS) were performed according to standard procedures. The test sample contained 979 individuals (mean age $54 \pm 11$ years). Forty-two percent had cancer, $22 \%$ chronic pain conditions, $10 \%$ depressive disorders, $6 \%$ other chronic diseases, and $20 \%$ were healthy.

Results: Reliability analysis of the 8-item pool revealed a good internal consistency coefficient (Cronbach's alpha $=.869)$, and a single-factor structure which explains $53 \%$ of variance. The BMLSS sum scores significantly differed with respect to the underlying disease, family status, duration of disease, and age. The highest scores were found in healthy individuals, and the lowest in patients with chronic pain conditions and depressive disorders. In cancer patients, the BMLSS correlated negatively with Depression/Anxiety (HADS), Fatigue (CFS-D), and positively with SF-12's mental health and to a weaker content also with physical health. Stepwise regression analyses revealed that life satisfaction can be predicted best by (the absence of) depression, but also by Conscious Living (AKU), which is an active cognitive-behavioral style in terms of adaptive coping.

Conclusions: The evaluation of the BMLSS revealed that the instrument has good psychometric properties and can be regarded as a brief, reliable and valid measure of LS in patients with chronic diseases. The instrument can be an important additive to existing health-related quality of life questionnaires, since it captures dimensions that contribute to quality of life but are not health related.
\end{abstract}

Key words: Life satisfaction, questionnaire, chronic diseases, patients

\section{BACKGROUND}

One area of psychology analyzes subjective well-being, people's cognitive and affective evaluation of their lives. This includes what one calls happiness, peace, fulfillment, and life satisfaction (LS) [1]. Although personality can explain a significant amount of variability in subjective-well-being, not only personal dispositions but also life circumstances influence long-term levels of subjective well-being, e.g., LS [1]. This unique dimension can be seen in the context of the conceptualizations of quality of life. Ferrans [2] differentiated five broad categories of quality of life, i.e., social utility, happiness/affect, normal life, achievement of personal goals, and satisfaction. LS is influenced by individuals' perception of certain aspects of life important to them, which may vary with respect to their importance between the individuals. These aspects can be regarded as external factors with an impact on quality of life, and thus can be considered as determinants [3].

To define the term 'satisfaction', one may argue that satisfaction is the extent of an individual's experience compared with his expectations. In terms of 'patients' satisfaction', this facet refers to medical care and service quality (which may impact health-related behavior), more specifically, to the extent to which general health care needs and condition-specific needs are met [4]. But 'life satisfaction' refers to a much broader concept. Even patients with impaired perception of health status, which may have more social needs, can have high satisfaction with various dimensions of life concerns. While it is true that patients with chronic disease may experience decreased quality of life and LS, it is not necessarily true for all individuals. Specifically, there is an increasing evidence that cancer patients not only experience traumatic stress, but in several cases also personal growth (reviewed in [5]). Moreover, in HIV infected individuals one may observe an increase of religiousness/spirituality which may predict slower disease progression [6]. While several patients may experience posttraumatic growth, mostly in the domain of appreciation of life, it was nevertheless not related to the level of psychological distress [7].

In six European countries, Borg et al. [8] investigated the relationship of LS to health, self-esteem, as well as social and financial resources among elderly with reduced functional capacity. In all national samples, overall health, self-esteem, and feeling worried, rather than activities of daily living capacity, were significantly associated with LS as measured with Life Satisfaction Index $Z$ scale [8]. The findings indicate the importance of taking not only the reduction in functional capacity into account but also the individual's perception of health and self-esteem. Personal rather than environmental factors are important for LS among people with reduced daily living capacity. 
On the basis of the '2005 Behavioral Risk Factor Surveillance System', an ongoing, state-based, randomdigit telephone survey, $6 \%$ of US adults were dissatisfied with their lives [9]. As the level of LS decreased, the prevalence of fair/poor general health, disability, and infrequent social support increased as did the mean number of days within one month of physical distress, mental distress, activity limitation, depressive symptoms, anxiety symptoms, sleep insufficiency, and pain; also the prevalence of smoking, obesity, physical inactivity, and heavy drinking increased with decreasing level of LS [9]. Moreover, adults with chronic illnesses were significantly more likely than those without to report life dissatisfaction [9]. Notably, all of these associations remained significant after adjusting for socio-demographic characteristics. Findings of Strine et al. [9] showed that health-related quality of life and health risk behaviors varied with the level of LS.

In most cases of chronic illness, there is no option of healing in terms of full physical and psychical restoration. However, although the 'medical model' refers to an optimal level of functioning, patients should not be reduced on their defects or illness-related deficiencies, instead one should bring forward concomitantly their potential for life and development. Thus, one has to ask for the underlying aspects of LS, which is of outstanding importance not just because patients with high satisfaction may be more active in their own health care, but also to identify specific (existential) needs which may impact the health-related needs and quality of life.

As LS appears to encompass many individual life domains, it may be an important concept for public health research. In fact, chronic illness affects not only physical and mental functioning, but also the working abilities, employment, and financial situation; and finally may have an impact on family life, friendships etc. Living with chronic disease and suffering obviously affects various aspects of life concerns. Consequently, it is of outstanding importance to improve physical and mental health conditions, and health-related quality of life. But the patients should not be reduced to their functional competence, i.e., physical symptoms and deficiencies, and thus one has to ask for the putative positive fields of life dimensions such as family life, friendships, living location, work, financial situation, generally oneself and overall life, and future perspectives. Several other variables may be important too. For example, several patients with chronic diseases, particularly patients with cancer, highly value spirituality/religiosity as a resource to deal with illness [10-14]. Also dimensions such as finding meaning and purpose in life are important issues [15], and how patients interpret their illness [16-18]. Recently, we were able to verify that perceptions of illness in terms of the positive disease interpretations 'challenge' and 'value' are correlated with adaptive coping strategies, while negative interpretations such as 'interruption/loss' and 'enemy/threat' were associated with depression and anxiety, and inversely with mental health-related quality of life and LS [16].

Melendez et al. found evidence of significant positive relations between psychological well-being dimensions and LS and between physical conditions and LS as well [19]. A structural model gave valuable information about the pattern of multivariate relationships among the variables. Physical and psychological wellbeing had a large effect on LS, albeit psychological wellbeing was the major predictor of LS [19]; a second result was that the influence of socio-demographic variables on LS were low, and they operated through the effects that maintain either on psychological well-being (or its individual indicators) or on physical conditions.

Because LS captures dimensions that contribute to quality of life, we intended to design a brief add-on scale to existing health-related quality of life questionnaires and referred to the work of Huebner and coworkers [20, 21]. This group has developed the 'Brief Multidimensional Students' Life Satisfaction Scale', which refers to the much longer 'Student's Life Satisfaction Scale (SLSS)'. This longer scale, which was designed to measure students' life satisfaction, demonstrated acceptable internal consistency and a uni-dimensional factor structure. In contrast to Diener's 5item 'Satisfaction with Life Scale' [22] with its very general domains, the 'Brief Multidimensional Students' Life Satisfaction Scale' addresses circumscribed aspects of students' life. However, to address certain aspects of life important to patients with chronic diseases, we intended (1) to determine the reliability of a modified LS scale, the 'Brief Multidimensional Life Satisfaction Scale' (BMLSS), in a sample of patients with chronic diseases (and some healthy individuals), and (2) to analyze the external validity of this instrument in terms of adaptive coping, mood, and healthrelated quality of life.

\section{Methods}

PARTICIPANTS

For this multicenter cross-sectional anonymous survey we analyzed the data of 979 individuals from already existing data pools of the hospitals mentioned below. Their institutional heads gave approval to run this anonymous survey. All subjects were informed of the purpose of the investigation, were assured of confidentiality, gave informed consent to participate, and completed the German language questionnaire by themselves which neither asked for names, initials, addresses or clinical details (with the exception of a diagnosis). The questionnaires were anonymous (and in accordance with similar instruments approved by the ethical commission of the University Witten/ Herdecke for current studies), and the pooled data could not be tracked back to the individual patients.

To minimize the bias of a sample of convenience, different recruiting centers were chosen. Patients with chronic diseases were recruited in the out-patient pain clinic of the Communal Hospital in Herdecke, the Orthopaedic Clinic in Bad Bocklet and the Baumrain Clinic in Bad Berleburg, the psychotherapeutic Oberberg Clinics Schwarzwald, Weserbergland and Berlin/ Brandenburg, and at a conference of breast cancer support groups in Magdeburg. Medical doctors from several West-German hospitals and medical practices served as healthy controls if they stated the absence of health affections. 
Because we intended to have a more complete picture, we had neither inclusion nor exclusion criteria (with the exception of children and adolescents). The patients from the psychotherapeutic Oberberg Clinics were at the moment of recruitment no active substance abusers.

\section{Demographic CharaCteristics}

The individuals ( $75 \%$ women) had a mean age of $54 \pm$ 11 years. Thirteen percent were $<40$ years of age (just 4 were $<20$ years of age), $24 \%$ between $41-50$ years, $34 \%$ between $51-60$ years, $25 \%$ between $61-70$ years, and $4 \%>70$ years. Most subjects were married $(63 \%)$ or lived with a partner not married with (8\%), 11\% lived alone, $10 \%$ were divorced, and $7 \%$ were widowed. A Christian affiliation was predominant (75\%), $3 \%$ had other religious affiliations and $22 \%$ had none. Twenty-nine percent had a secondary education (Hauptschule), 20\% a junior high school education (Realschule), 41\% a high school education (Gymnasium), $9 \%$ other, and $<1 \%$ none.

Forty-two \% had cancer, $22 \%$ chronic pain conditions (among them, 20\% fibromyalgia, 17\% spine-associated pain syndromes such as chronic back pain etc., $8 \%$ limp amputations and phantom pain, $6 \%$ polyarthritis, 4\% migraine/headache, and various other chronic pain conditions), $10 \%$ depressive disorders with/without alcohol addiction, $6 \%$ other chronic diseases, and $20 \%$ healthy individuals.

\section{Measures and Statistical Analysis}

The items of the LS scale were derived from the 6item 'Brief Multidimensional Students' Life Satisfaction Scale' $[20,21]$ and from physicians input, i.e., Family Life; Friendships; Work (replaced the item School); Myself; Where I live; Overall Life; and two new items, i.e., Financial Situation and Future Prospects.

The eight items of the BMLSS (Table 1) refer to intrinsic dimensions (Myself, Overall Life), social dimensions (Friendships, Family life), external dimension (Work, Where I live), and the perspective dimension (Financial Situation, Future Prospects). Items referring to the health situation were intentionally not included and should be measured with a specific health-related quality of life tool. (However, BMLSS Version 2 heeds three additional items, i.e. health situation, effectiveness of treatment, and own abilities to deal with daily life.)
Each item was introduced by the phrase: "I would describe my satisfaction with ...", and scored on a 7point scale from dissatisfaction to satisfaction $(0$ - Terrible; 1 - Unhappy; 2 - Mostly dissatisfied; 3 - Mixed (about equally satisfied and dissatisfied); 4 - Mostly satisfied; 5 - Pleased; 6 - Delighted). The BMLSS sum score was referred to a 100\% level ("Delighted").

Data were treated as ordinal data. The reliability of the scale was evaluated with internal consistency coefficients, which reflect the degree to which all items on a particular scale measure a single (uni-dimensional) concept. To combine several items with similar content, we relied on the technique of factor analysis (extraction of main components with Eigenvalues $>1$ ), which examines the correlations among a set of variables in order to achieve a set of more general 'factors'. Factor analyses were repeated rotating different numbers of items (Varimax rotation with Kaiser Normalization) in order to arrive at a solution embodying both the simplest structure and the most coherent one.

To analyze the external validity, the BMLSS scale was correlated with the Hospital Anxiety and Depression Scale (HADS [21, 23]); Escape from illness, an add-on scale of the AKU questionnaire [13, 24]; the Cancer Fatigue Scale (CFS-D [25]); and physical and mental health-related quality of life as measured with the Medical Outcomes Study Short-Form Health Survey SF-12 $[26,27]$. Adaptive coping styles were measured with the AKU questionnaire (AKU is an acronym of the German translation of "Adaptive Coping with Disease") $[13,28,29]$, which refers to the concept of an internal respectively an external locus of disease control. The instrument differentiates 6 factors (i.e., Conscious Way of Living; Positive Attitudes; Reappraisal: Illness as Chance; Trust in Medial Help; Search for Information and Alternative Help; Trust in God's Help).

Reliability and factor analyses, analyses of variance (ANOVA), correlation (Spearman rho) and stepwise regression analyses were performed with SPSS 15.0 for Windows (SPSS GmbH Software, Munich). We considered a level of $\mathrm{p}<0.05$ as statistically significant.

\section{RESULTS}

\section{RELIABILITY AND FACTOR ANALYSIS}

As shown in Table 1 , reliability analysis of the 8 -item pool revealed that the construct had a good internal

Table 1. Mean values and reliability parameters. One component extracted (Eigenvalue 4.2): 53\% of explained variance.

\begin{tabular}{lccccc}
\hline BMLSS Items & $\begin{array}{c}\text { Mean } \pm \text { SD } \\
\text { (Score 0-6) }\end{array}$ & $\begin{array}{c}\text { Difficulty Index } \\
(=0.69)\end{array}$ & Factor loading & $\begin{array}{c}\text { Corrected Item-Total } \\
\text { Correlation }\end{array}$ & $\begin{array}{c}\text { Alpha if Item Deleted } \\
\text { (alpha }=0.869)\end{array}$ \\
\hline Overall Life & $4.35 \pm 1.30$ & .73 & .865 & .792 & .835 \\
Future Prospects & $3.87 \pm 1.45$ & .65 & .794 & .708 & .843 \\
Myself & $4.07 \pm 1.32$ & .51 & .780 & .682 & .847 \\
Family Life & $4.54 \pm 1.43$ & .76 & .698 & .587 & .857 \\
Financial Situation & $3.99 \pm 1.53$ & .67 & .687 & .584 & .858 \\
Friendships & $4.64 \pm 1.23$ & .77 & .673 & .569 & .859 \\
Where I live & $4.69 \pm 1.21$ & .78 & .670 & .565 & .859 \\
Work/Working place & $3.81 \pm 1.47$ & .64 & .628 & .525 & .865
\end{tabular}


Table 2. Correlation analyses between life satisfaction dimensions. All variables were significant at the 0.01 level (Pearson Correlation; 2-tailed). Strong correlations were highlighted.

\begin{tabular}{|c|c|c|c|c|c|c|c|c|}
\hline & $\begin{array}{c}\text { Family } \\
\text { Life }\end{array}$ & $\begin{array}{l}\text { Friend- } \\
\text { ships }\end{array}$ & Work & Myself & $\begin{array}{l}\text { Where } \\
\text { I live }\end{array}$ & $\begin{array}{c}\text { Overall } \\
\text { live }\end{array}$ & $\begin{array}{l}\text { Financial } \\
\text { Situation }\end{array}$ & $\begin{array}{c}\text { Future } \\
\text { Prospects }\end{array}$ \\
\hline Family Life & 1 & ,493 & ,306 & ,493 & ,411 & 608 & ,350 & ,492 \\
\hline Friendships & & 1 & ,391 & ,460 & ,420 & ,509 & ,303 & ,389 \\
\hline Work & & & 1 & ,453 &, 323 & ,437 & ,390 & ,451 \\
\hline Myself & & & & 1 & ,443 & ,691 & ,403 & ,587 \\
\hline Where I live & & & & & 1 &, 524 & ,404 & ,401 \\
\hline Overall Live & & & & & & 1 & ,536 & ,664 \\
\hline Financial Situation & & & & & & & 1 & ,611 \\
\hline Future Prospects & & & & & & & & 1 \\
\hline
\end{tabular}

Table 3. Life satisfaction scores and demographic data. Results are mean values and SD. The LS sum score refers to a $100 \%$ level.

\begin{tabular}{|c|c|}
\hline & LSS Sum Score $(\%)$ \\
\hline Total & $72.5 \pm 17.0$ \\
\hline \multicolumn{2}{|l|}{ Gender } \\
\hline Women & $72.6 \pm 17.1$ \\
\hline Men & $72.3 \pm 16.8$ \\
\hline F-value (df) & $0.050(944)$ \\
\hline $\mathrm{p}$-value & n.s. \\
\hline \multicolumn{2}{|l|}{ Age groups } \\
\hline$\leq 40$ years of age & $69.1 \pm 18.2$ \\
\hline $41-50$ years of age & $69.9 \pm 17.1$ \\
\hline $51-60$ years of age & $72.5 \pm 16.9$ \\
\hline $61-70$ years of age & $76.0 \pm 16.1$ \\
\hline$>70$ years of age & $78.2 \pm 13.1$ \\
\hline F-value (df) & $6.224(952)$ \\
\hline $\mathrm{p}$-value & $\mathrm{p}<0.001$ \\
\hline \multicolumn{2}{|l|}{ Family status } \\
\hline Married & $75.2 \pm 15.6$ \\
\hline With partner & $71.4 \pm 17.5$ \\
\hline Divorced & $65.6 \pm 17.2$ \\
\hline Living alone & $63.9 \pm 20.7$ \\
\hline Widowed & $74.8 \pm 13.9$ \\
\hline F-value (df) & $12.810(937)$ \\
\hline $\mathrm{p}$-value & $\mathrm{p}<0.001$ \\
\hline \multicolumn{2}{|l|}{ Disease groups } \\
\hline Healthy individuals & $77.6 \pm 13.2$ \\
\hline Cancer & $75.9 \pm 15.7$ \\
\hline Chronic pain conditions & $65.4 \pm 17.0$ \\
\hline Other chronic diseases & $73.0 \pm 16.1$ \\
\hline Depression ( \pm addiction) & $63.0 \pm 20.7$ \\
\hline F-value (df) & $28.208(959)$ \\
\hline p-value & $\mathrm{p}<0.001$ \\
\hline \multicolumn{2}{|l|}{ Duration of disease } \\
\hline$<6$ months & $73.8 \pm 18.2$ \\
\hline 6-12 months & $74.5 \pm 16.8$ \\
\hline $1-3$ years & $70.8 \pm 17.1$ \\
\hline $3-5$ years & $65.6 \pm 19.8$ \\
\hline$>5$ years & $63.3 \pm 18.1$ \\
\hline F-value $(\mathrm{df})$ & $6.592(426)$ \\
\hline $\mathrm{p}$-value & $\mathrm{p}<0.001$ \\
\hline
\end{tabular}

consistency (Cronbach's alpha $=0.869)$. The item difficulty (4.12 [mean value] / 6) was 0.69, and none of the items exceeded the acceptable range of 0.2 to 0.8 .

Factor analysis revealed a Kaiser-Mayer-Olkin value of .887, which as a measure for the degree of common variance, indicates that the item-pool seems to be suitable for a factorial validation. Primary factor analysis pointed to a 1 -factor solution (initial Eigenvalue $=$ 4.2), which explains $53.1 \%$ of variance (Table 1$)$. The more general item Overall Life had the strongest factor loading, the item Work the lowest. The mean scores of the 8 items ranged from 3.81 ("mostly satisfied") to 4.69 ("pleased"), i.e., the lowest scores were found for Work and Future Prospects, and the highest for Where I live and Friendships (Table 1). The various LS dimensions correlated strongly with Overall Life (Table 2), particularly the items Myself $(r=0.69)$ and Future Prospects $(r=0.66)$, indicating that Overall Live is a broad and general dimension.

\section{IMPACT OF SOCIO-DEMOGRAPHIC VARIABLES}

As shown in Table 3, the BMLSS sum scores significantly differed with respect to the underlying disease $(\mathrm{F}=28.208)$, family status $(\mathrm{F}=12.810)$, duration of disease $(F=6.592)$, and age $(F=6.224)$, but not for gender $(\mathrm{F}=0.050$; n.s.) or religious denomination ( $\mathrm{F}$ $=2.258$; n.s.). We observed higher LS score also in individuals with a higher educational level $(\mathrm{F}=3.103$; df $=942 ; \mathrm{p}=0.015)$; but because the healthy individuals almost had the highest educational level, this variable should not be overinterpreted.

In general, the highest LS scores were found in healthy individuals, and the lowest in patients with chronic pain conditions and depressive disorders (Table 3). Moreover, individuals with higher age, those who were married or widowed, and patients with a shorter course of disease had better BMLSS scores than individuals of younger age $(<50$ years of age), longer course of disease ( $>3$ years), and those divorced or living alone. Thus, from a theoretical point of view, these differences are plausible.

Among the patients, those with cancer had the highest LS scores. However, Escape from illness was the lowest in cancer patients as compared to other patients; the highest scores were found in patients with chronic pain conditions $(\mathrm{F}=37.953$; $\mathrm{df}=731 ; \mathrm{p}$ $<0.001)$. 


\section{CONSTRUCT VALIDITY}

Among the whole group of patients, we correlated the BMLSS scores with adaptive coping styles (AKU) and Escape from illness. As shown in Table 4, LS correlated moderately particularly with intrinsic adaptive coping strategies such as Positive Attitudes and Conscious Living (which are active cognitive-behavioral styles), and moderately negative with Escape from illness (which is an escape-avoidance strategy).

In cancer patients, the LS correlated strongly (inverse) with Anxiety and Depression, moderately (inverse) with Fatigue, and moderately (positive) with mental health-related quality of life, while physical health correlated weakly (Table 4).

Table 4. External correlation. $* \mathrm{p}<0.01$ (Spearman rho; 2tailed). Strong correlations were highlighted.

\begin{tabular}{lcc}
\hline & \multicolumn{2}{c}{ Life Satisfaction } \\
& $\begin{array}{c}\text { Whole } \\
\text { sample }\end{array}$ & $\begin{array}{c}\text { Cancer } \\
\text { patients }\end{array}$ \\
\hline Adaptive Coping & $.355^{*}$ & $.251^{*}$ \\
Positive Attitudes & $.353^{*}$ & $.278^{*}$ \\
Conscious Living & .070 & .048 \\
Reappraisal: Illness as Chance & .024 & .095 \\
Trust in Medical Help & .058 & .000 \\
Search for Information/ & & \\
Alternative Help & $.141^{*}$ & .088 \\
Trust in God's Help & $-.364^{*}$ & $-.283^{*}$ \\
Escape from Illness & - & $-.541^{*}$ \\
Anxiety & - & $-.642^{*}$ \\
Depression & - & $-.425^{*}$ \\
Fatigue & - & $.232^{*}$ \\
Physical health & - & $.418^{*}$ \\
Mental health & & \\
\hline
\end{tabular}

In patients with depressive disorders (with or without alcohol addiction), the BMLSS correlated negatively with Beck's Depression Index $(r=-0.669 ; \mathrm{p}$ $<0.0001$ ), which confirms the results observed in the cancer patients.

Stepwise regression analyses revealed that LS can be predicted best by (the absence of) depression (Beta $=-0.571 ; \mathrm{p}<0.001)$, but also by Conscious Living (Beta $=0.163 ; \mathrm{p}=0.007)$. The predictive power of the model was sufficiently high $(\mathrm{R} 2=0.410)$. Excluded variables were anxiety; Escape from Illness; fatigue; SF-12's health related quality of life; age; duration of disease, and other adaptive coping strategies.

\section{Discussion}

The concept of LS goes far beyond patients' functional competence and health satisfaction. Even patients with impaired perception of health status, which may have more social needs, can have high satisfaction with various dimensions of life concerns. To operationalize this concept and to evaluate a brief and compact scale to measure LS, which can easily be incorpo- rated as an important additive to existing health-related quality of life questionnaires, we have developed the BMLSS. This tool captures dimensions that contribute to quality of life but are not health related. We can state that the 8-item instrument had a good internal consistency coefficient, and a single-factor structure which explains $53 \%$ of variance. External validation revealed positive associations of the BMLSS with health-related quality of life and intrinsic coping strategies, and negative associations with depression, anxiety, fatigue, and an escape-avoidance strategy. Regression analyses revealed that LS can be predicted best by (the absence of) depression and by Conscious Living, which is a active cognitive-behavioral style in terms of adaptive coping [13,29]. This is in line with the finding of others that particularly psychological well-being was is a major predictor of LS [19].

Among the patients, those with cancer had the highest LS scores. This could be due to the fact that cancer patients were significantly older than the others, while healthy individuals and patients with depressive disorders were the youngest ( $F=87.279$; $\mathrm{p}<0.0001$ ); thus, higher LS can be explained by higher age, too. Another important finding of this analysis was that LS scores of cancer patients were similar to healthy individuals, despite of their fatal diagnosis. As reported previously, cancer patients do not necessarily regard illness as a dispensable interrupt of life, but also as a challenge, a chance to reflect and to change life and behavior $[10,12,16]$. A recent review on posttraumatic growth in cancer patients confirms significant differences between patients with cancer and other traumas [30], among them differences in the interpretation of cancer as a future, ongoing and chronic integration threat, and also uncertainty and vulnerability.

In contrast, patients with chronic pain conditions and depressive disorders had significantly lower LS scores than patients with cancer. One may suggest that hope, as an important aspect in health-related quality of live, is much higher in cancer patients, while particularly patients with chronic pain conditions may have experienced the limitations of the health care system in regard of an effective pain management. Thus, their frustration might be much higher, which in turn decreases satisfaction with life. A hint which would support this suggestion could be a significantly lower Escape from illness in cancer patients than in patients with chronic pain conditions.

Within this context one may discuss also the concept of reframing (which means to understand and use multiple perspectives), i.e., patients with chronic diseases have to re-adjust their life expectations to the new condition, and in relation to that - reframed - expectation, they could be just as satisfied as other persons. In fact, to find meaning in the chronic illness process involves a patient's assenting to the illness and reframing its implications positively [15]. Schroevers and Teo [7] stated that "greater use of the coping strategies instrumental support, positive reframing, and humor was associated with more posttraumatic growth". Patients with chronic diseases are thus not exclusively 'functionally deficient' (albeit the symptoms of disease may persist), because several aspects of life concerns may be vital and important to them. 
The priority of these aspects may vary between the individuals depending on various variables.

Taken together, our BMLSS scale has important strengths, i.e., it is compact, multimodal, and applicable to patients with chronic diseases. Its brief nature allows it to be easily added to large surveys that can include only a few extra questions on this dimension. In contrast to the general domains of Diener's 5-item 'Satisfaction with Life Scale' [22] (i.e., In most ways my life is close to my ideal; The conditions of my life are excellent; I am satisfied with my life; So far I have gotten the important things I want in life; If I could live my life over, I would change almost nothing), the BMLSS addresses individuals' perception of circumscribed aspects of life important to them. These items thus can prioritize LS aspects relevant for the individual.

A limitation of our study was the overrepresentation of women, and the fact that we had a dominance of patients with cancer and chronic pain conditions, which might not be representative for the general population of people living with chronic disease. Nevertheless, further work has to be done in validating this instrument in longitudinal and interventional studies.

\section{CONCLUSIONS}

The evaluation of the BMLSS revealed that the instrument has good psychometric properties. The scale can be an important additive to existing health-related quality of life questionnaires, since it captures dimensions that contribute to quality of life but are not health related. The fact that LS was inversely associated with mood states, and positively with health-related quality of life and the intrinsic adaptive coping, indicates that this instrument may be used to examine the effect of positive coping with chronic disease on LS.

Acknowledgements: We highly appreciate the contribution of Hans-Joachim Balzat (Pain Outpatient Clinic, Communal Hospital in Herdecke), Dr. Ralf-Achim Grünther (Orthopaedic Clinic in Bad Bocklet and Baumrain Clinic in Bad Berleburg), Prof. Dr. Götz Mundle (Oberberg Clinic Schwarzwald), and several others who encouraged their patients to fill out the questionnaires.

\section{REFERENCES}

1. Diener E, Oishi S, Lucas RE: Personality, culture, and subjective well-being: emotional and cognitive evaluations of life. Annu Rev Psychol 2003, 54: 403-425.

2. Ferrans CE: Conceptualizations of quality of life in cardiovascular research. Prog Cardiovasc Nurs 1992, 7: 2-6.

3. Moons P, Marquet K, Budts W, De GS: Validity, reliability and responsiveness of the "Schedule for the Evaluation of Individual Quality of Life-Direct Weighting" (SEIQoL-DW) in congenital heart disease. Health Qual Life Outcomes 2004, 2: 27.

4. Asadi-Lari M, Tamburini M, Gray D: Patients' needs, satisfaction, and health related quality of life: towards a comprehensive model. Health Qual Life Outcomes 2004, 2: 32.

5. Jim HS, Jacobsen PB: Posttraumatic stress and posttraumatic growth in cancer survivorship: a review. Cancer J 2008, 14: 414-419.

6. Ironson G, Stuetzle R, Fletcher MA: An increase in religiousness/spirituality occurs after HIV diagnosis and pre- dicts slower disease progression over 4 years in people with HIV. J Gen Intern Med 2006, 21 Suppl 5: S62-S68.

7. Schroevers MJ, Teo I: The report of posttraumatic growth in Malaysian cancer patients: relationships with psychological distress and coping strategies. Psychooncology 2008, 17: 1239-1246.

8. Borg C, Fagerstrom C, Balducci C, Burholt V, Ferring D, Weber $G$ et al.: Life satisfaction in 6 European countries: the relationship to health, self-esteem, and social and financial resources among people (Aged 65-89) with reduced functional capacity. Geriatr Nurs 2008, 29: 4857.

9. Strine TW, Chapman DP, Balluz LS, Moriarty DG, Mokdad AH: The associations between life satisfaction and health-related quality of life, chronic illness, and health behaviors among U.S. community-dwelling adults. J Community Health 2008, 33: 40-50.

10. Büssing A, Ostermann T, Matthiessen PF: Search for meaningful support and the meaning of illness in German cancer patients. Anticancer Res 2005, 25: 1449-1455.

11. Büssing A, Ostermann T, Matthiessen PF: Role of religion and spirituality in medical patients: confirmatory results with the SpREUK questionnaire. Health Qual Life Outcomes 2005, 3: 10.

12. Büssing A, Ostermann T, Koenig HG: Relevance of religion and spirituality in German patients with chronic diseases. Int J Psychiatry Med 2007, 37: 39-57.

13. Büssing A, Ostermann T, Matthiessen PF: Adaptive coping and spirituality as a resource in cancer patients. Breast Care 2007, 195-202.

14. Büssing A, Fischer J, Ostermann T, Matthiesen P.F.: Reliance on God's help, depression and fatigue in female cancer patients. Int J Psychiatry Med 2008, 38: 357-372.

15. Baker C, Stern PN: Finding meaning in chronic illness as the key to self-care. Can J Nurs Res 1993, 25: 23-36.

16. Büssing A, Fischer J: Interpretation of illness in cancer survivors is associated with health-related variables and adaptive coping styles. BMC Women's Health 2009, (in press).

17. Degner LF, Hack T, O'Neil J, Kristjanson LJ: A new approach to eliciting meaning in the context of breast cancer. Cancer Nurs 2003, 26: 169-178.

18. Wallberg B, Michelson H, Nystedt M, Bolund C, Degner L, Wilking N: The meaning of breast cancer. Acta Oncol 2003, 42: 30-35.

19. Melendez JC, Tomas JM, Oliver A, Navarro E: Psychological and physical dimensions explaining life satisfaction among the elderly: A structural model examination. Arch Gerontol Geriatr 2008, (in press).

20. Huebner ES, Suldo S, Valois RF, Drane JW, Zullig K: Brief multidimensional students' life satisfaction scale: sex, race, and grade effects for a high school sample. Psychol Rep 2004, 94: 351-356.

21. Zullig KJ, Huebner ES, Gilman R, Patton JM, Murray KA: Validation of the brief multidimensional students' life satisfaction scale among college students. Am J Health Behav 2005, 29: 206-214.

22. Diener E, Emmons RA, Larsen RJ, Griffin S: The Satisfaction With Life Scale. J Pers Assess 1985, 49: 71-75.

23. Herrmann C: International experiences with the Hospital Anxiety and Depression Scale--a review of validation data and clinical results. J Psychosom Res 1997, 42: 17-41.

24. Büssing A, Keller N, Michalsen A, Moebus S, Ostermann T, Matthiessen PF: Spirituality and Adaptive Coping Styles in German Patients with Chronic Diseases in a CAM Health Care Setting. Journal of Complementary and Integrative Medicine 2006, 3: 1-16.

25. Kröz M, Zerm R, Reif M, Laue HBv, Schad F, Büssing A et al.: Validation of the German version of the Cancer Fatigue Scale (CFS-D). Eur J Cancer Care (Engl) 2008, 17: 33-41. 
26. Resnick B, Nahm ES: Reliability and validity testing of the revised 12-item Short-Form Health Survey in older adults. J Nurs Meas 2001, 9: 151-161.

27. Ware J, Jr., Kosinski M, Keller SD: A 12-Item ShortForm Health Survey: construction of scales and preliminary tests of reliability and validity. Med Care 1996, 34: 220-233.

28. Büssing A, Keller N, Michalsen A, Moebus S, Ostermann T, Matthiessen PF: Spirituality and Adaptive Coping Styles in German Patients with Chronic Diseases in a CAM Health Care Setting. Journal of Complementary and Integrative Medicine 2008, 3: 1-16.

29. Büssing A, Ostermann T, Matthiessen PF: Wer kontrolliert die Gesundheit? - Adaptive Krankheitsverarbeitungsstile bei Patienten mit chronischen Erkrankungen. Deutsche Zeitschrift für Onkologie 2008, 40: 150156.
30. Sumalla EC, Ochoa C, Blanco I: Posttraumatic growth in cancer: reality or illusion? Clin Psychol Rev 2009, 29: 24-33.

Received: October 16, 2008 / Accepted: February 24, 2009

Address for correspondence:

Prof. Dr. med. Arndt Büssing

Chair of Medical Theory and Complementary Medicine

University of Witten/Herdecke

Gerhard-Kienle-Weg 4

58313 Herdecke

Germany

Phone: +49-2330/623246

Fax: $\quad+49-2330 / 623358$

Email: arndt.buessing@uni-wh.de 